\title{
A Comparison Study of Velocity Controller of Indirect Field Oriented Control of Linear Induction Motor Drive Using Model Predictive Controller
}

\author{
Fatimah F. Jaber ${ }^{1}$, Diyah K. Shary ${ }^{2}$, and Haider Alrudainy ${ }^{3}$ \\ \{fatimah.jaber@stu.edu.iq ${ }^{1}$, diyahpower@stu.edu.iq ${ }^{2}$, h.m.a.Alrudainy@stu.edu.iq $\left.{ }^{3}\right\}$ \\ Southern Technical University, Engineering Technical College, Basra, Iraq 1,2,3
}

\begin{abstract}
Controlling the velocity of indirect field-oriented control of linear induction motor (LIM) drive is recently receiving significant attention. In this paper, a comparison study in connection to response time and resilience using two different controllers including PID and model predictive control (MPC) is extensively investigated. Two vector control systems for LIM drive are introduced in this study. The first drive mechanism uses a traditional PID controller to control the LIM's velocity. For effective control, whereas, MPC has been adopted to monitor the LIM velocity in the second drive system. Therefore, the performance of these controllers under parameters variation conditions and load disturbance has been compared. MATLAB simulation toolbox has been utilized, in this work, to demonstrate the feasibility of the two suggested schemes. The results showed that MPC based approach is superior to the traditional PID-based drive controller in terms of load disturbances and parameter variations.
\end{abstract}

Keywords: Linear induction motor (LIM), PID controller, indirect field-oriented control (IFOC), and model predictive control (MPC).

\section{Introduction}

Due to its remarkable advantages including direct producing thrust force, low cost, simple structure, high acceleration/deceleration, and easy maintenance, the linear induction motor is practical in areas that require linear motion. As a result, LIMs are still commonly utilized in a wide range of implementations, such as transportation, pumping of liquid metal, actuators, sliding door closers, conveyor systems, and so on [1]. The feedback linearization and fieldoriented control (Vector Control) methods have made high-performance implementations of induction motor drives feasible owing to rapid progress in microelectronics and power electronic devices. Nevertheless, the motor's parameters must be precisely defined, and the correct flux data must be accurately measured to be effectively used in various applications. Besides, the performance of these motors is significantly impacted by the variations of motor parameters and unknown external disturbances [2], [3].

PID controllers are frequently utilized in industrial applications like motor control because of their simple construction and quick parameter adjustment [4]. The PID formulas are simple and can be easily applied to various controlled plants, but if the process is highly ordered and nonlinear, it may not yield good control results [5]. Both in the industry and the research control community, model predictive control (MPC) has advanced significantly in recent years. The model predictive control can find the optimum solution while keeping the constraints in mind 
[6]. As a result, a plethora of exploratory research demonstrated that MPC can be significantly effective in such processes than the PID controller counterparts [7], [8].

This work provides a comparison of various controlling schemes for an IFOC drive of a linear induction motor. The major contributions of this work can be summarized as follow:

1- Various controls have been used to monitor the LIM drive's velocity.

2- To validate our schemes a computer simulation has been adopted.

3- To investigate which controller is resistant to load disturbances and motor parameter variations.

\section{Background}

Controlling the velocity of linear induction motors has been the subject of a slew of research papers in recent years, as seen in Table 1. In [9] the speed control of a single-side LIM using model fuzzy predictive force control (FPFC) is presented. This study [10] has been used a proposed controller dependent on an optimal recurrent wavelet neural network with a PID controller to control the velocity, thrust force, and the stator current of a 3-phase linear induction motor that considering the end effects. Using the particle swarm optimization technique, the proposed controller is tuned online. In [11] suggests a novel secondary field-oriented control model of LIM that depends upon a fuzzy self-adapting PI controller that takes the impact of the longitudinal end effect into account. This work [12] provides an optimal $P I^{\lambda} D^{\mu}$ controller with 2DOF and anti-windup strategies depend upon PSO Optimization, which is utilized to control the linear induction motor velocity. In [13] the LIM speed control method is proposed in this study, which leads to optimal control of motor characteristics like, flux, current, and thrust based on the DTFC method. DTFC is a more developed control approach that employs several PI controllers.

Table 1. Literature review of approaches used to control LIM.

\begin{tabular}{|c|c|c|c|}
\hline Ref. & Approaches & Advantages & Disadvantages \\
\hline [9] & $\begin{array}{l}\text { Model fuzzy } \\
\text { predictive force } \\
\text { control (FPFC) }\end{array}$ & $\begin{array}{l}\text { Lower force ripple and } \\
\text { a faster convergence } \\
\text { speed }\end{array}$ & $\begin{array}{l}\text { The accurate measurement of force and flux } \\
\text { is critical to the FPFC's successful service }\end{array}$ \\
\hline [10] & RWNN+PID & $\begin{array}{l}\text { Efficient and provides } \\
\text { preferred and rigorous } \\
\text { performance }\end{array}$ & Very complex \\
\hline [11] & $\begin{array}{l}\text { Fuzzy Self- } \\
\text { adapting PI } \\
\text { Controller }\end{array}$ & $\begin{array}{l}\text { Robust and respond } \\
\text { quickly to new dynamic } \\
\text { procedures }\end{array}$ & $\begin{array}{l}\text { One of the most frequently mentioned } \\
\text { drawbacks of fuzzy logic methods is the lack } \\
\text { of adequate resources for analysing the } \\
\text { controller's results, such as stability, } \\
\text { optimality, robustness, and so on }\end{array}$ \\
\hline [12] & $\begin{array}{l}P I^{\lambda} D^{\mu}+ \\
\text { 2DOF+ anti- } \\
\text { windup } \\
\text { strategies } \\
\text { depend upon } \\
\text { PSO }\end{array}$ & $\begin{array}{l}\text { Powerful in terms of } \\
\text { improving the motor's } \\
\text { performance }\end{array}$ & $\begin{array}{l}\text { PSO has several drawbacks, including the } \\
\text { inability to address scattering problems, the } \\
\text { difficulty in defining initial design } \\
\text { parameters, and the possibility of converging } \\
\text { early and being stuck in a local minimum } \\
\text { while dealing with complicated problems }\end{array}$ \\
\hline
\end{tabular}




\section{LIM Model}

The linear induction motor model can be studied by using the $\mathrm{d}-\mathrm{q}$ axis equivalent circuit as shown in Fig 1. which considers the end effects? The q-axis circuit of LIM is analogous to the $\mathrm{q}$-axis circuit of a rotating induction motor. Where the q-axis circuit parameters do not vary with the end effects. Because secondary direct-axis entrance currents reduce the direct-axis secondary flux linkage $\left(\lambda_{d r}\right)$, the d-axis circuit of the rotary induction motor cannot be utilized in a LIM study when end effects are considered [14]:

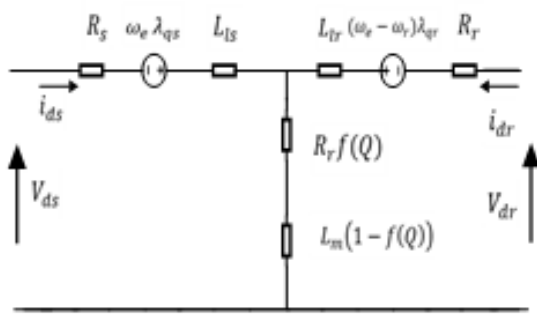

(a)

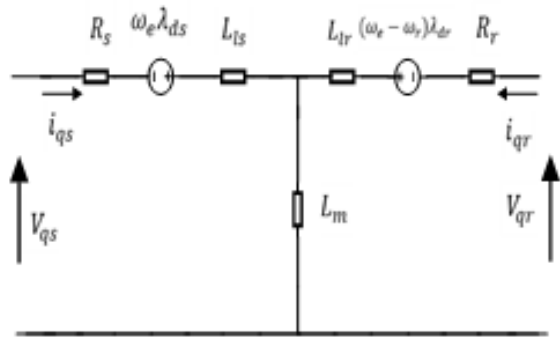

(b)

Fig 1. Demonstrates: (a) LIM's d-axis electrical circuit; (b) LIM's q-axis electrical circuit.

Based upon the d-q axis electrical circuit, the voltage equations of primary and secondary (linor) are described in differential equations in the synchronous reference frame given below [14]:

$\mathrm{V}_{\mathrm{ds}}=\mathrm{R}_{\mathrm{s}} \mathrm{i}_{\mathrm{ds}}+\mathrm{R}_{\mathrm{r}} \mathrm{f}(\mathrm{Q})\left(\mathrm{i}_{\mathrm{ds}}+\mathrm{i}_{\mathrm{dr}}\right)+\mathrm{p} \lambda_{\mathrm{ds}}-\omega_{\mathrm{e}} \lambda_{\mathrm{qs}}$

$\mathrm{V}_{\mathrm{qs}}=\mathrm{R}_{\mathrm{s}} \mathrm{i}_{\mathrm{qs}}+\mathrm{p} \lambda_{\mathrm{qs}}+\omega_{\mathrm{e}} \lambda_{\mathrm{ds}}$

$\mathrm{V}_{\mathrm{dr}}=\mathrm{R}_{\mathrm{r}} \mathrm{i}_{\mathrm{dr}}+\mathrm{R}_{\mathrm{r}} \mathrm{f}(\mathrm{Q})\left(\mathrm{i}_{\mathrm{ds}}+\mathrm{i}_{\mathrm{dr}}\right)+\mathrm{p} \lambda_{\mathrm{dr}}-\omega_{\mathrm{sl}} \lambda_{\mathrm{qr}}$

$\mathrm{V}_{\mathrm{qr}}=\mathrm{R}_{\mathrm{r}} \mathrm{i}_{\mathrm{qr}}+\mathrm{p} \lambda_{\mathrm{qr}}+\omega_{\mathrm{sl}} \lambda_{\mathrm{dr}}$

Where, $\left(\mathrm{V}_{\mathrm{ds}}, \mathrm{V}_{\mathrm{qs}}\right)$ and $\left(\mathrm{V}_{\mathrm{dr}}, \mathrm{V}_{\mathrm{qr}}\right)$ represents the primary and linor voltages in the directquadrature axis respectively, $\mathrm{R}_{\mathrm{s}}$ and $\mathrm{R}_{\mathrm{r}}$ represents the primary and linor resistance respectively, $\left(\mathrm{i}_{\mathrm{ds}}, \mathrm{i}_{\mathrm{qs}}\right)$ and $\left(\mathrm{i}_{\mathrm{dr}}, \mathrm{i}_{\mathrm{qr}}\right)$ represents the primary and linor direct-quadrature currents respectively, $\mathrm{p}$ represents the differential operator, $\left(\lambda_{\mathrm{ds}}, \lambda_{\mathrm{qs}}\right)$ and $\left(\lambda_{\mathrm{dr}}, \lambda_{\mathrm{qr}}\right)$ represents flux linkage of the primary and linor in direct -quadrature axis respectively, $\omega_{\mathrm{e}}$ represents the angular velocity of the primary, $\omega_{\text {sl }}$ represents the slip frequency, and $Q$ represents the factor linked to the primary length. $f(Q)$ is indicated as:

$f(Q)=\frac{1-e^{-Q}}{Q}$ 
Where,

$Q=\frac{D * R_{r}}{L_{r} v_{r}}$

Where, $\mathrm{D}, L_{r}$, and $v_{r}$ represents the LIM length, linor self-inductance, and LIM velocity respectively. The primary and secondary flux linkages can be described as [14]:

$\lambda_{d s}=L_{l s} i_{d s}+L_{m}(1-f(Q))\left(i_{d s}+i_{d r}\right)$

$\lambda_{q s}=L_{l s} i_{q s}+L_{m}\left(i_{q s}+i_{q r}\right)$

$\lambda_{d r}=L_{l r} i_{d r}+L_{m}(1-f(Q))\left(i_{d s}+i_{d r}\right)$

$\lambda_{q r}=L_{l r} i_{q r}+L_{m}\left(i_{q s}+i_{q r}\right)$

Where, $L_{l s}$, and $L_{l r}$ represents the leakage inductance of the primary and linor respectively, and $L_{m}$ represents the mutual inductance. Thrust Force of linear induction motor can be described as [14]:

$F e=\frac{3 \pi P}{2 \tau_{p} 2}\left(\lambda_{d s} i_{q s}-\lambda_{q s} i_{d s}\right)=M . v^{\prime}+B . v+F_{L}$

Where $\mathrm{P}$ represents the number of poles, $\tau_{p}$ is the pole pitch, $M$ is the total mass of the moving part, and $B$ is the viscous friction.

\section{Indirect Field-Oriented Control of LIM}

The IFOC of LIM is not as simple as the rotary induction motor due to the new resistance and inductance in the excitation branch, both of which are dependent on the motor velocity. As a result, decoupling the thrust and speed is more difficult. In ideally field-oriented control, the secondary flux linkage axis is forced to align with the direct-axis, yielding in [15], [16]:

$\lambda_{q r}=\frac{d \lambda_{q r}}{d t}=0$

$\lambda_{d r}=\lambda_{r}=$ constant

The thrust force demonstrated in (11) can be accurately expressed by the following equation using the IFOC method and given that the electrical time constant is much smaller than the mechanical time constant:

$F_{e}=k_{f} \cdot i_{q s}$

Where;

$k_{f}=\frac{3 \pi}{2 \tau_{p}} P \frac{L_{m}(1-f(Q))}{L_{r}-L_{m} f(Q)} \lambda_{d r}$

Furthermore, using (3) the feed-forward slip velocity signal is: 
$V_{s l}=\frac{\tau_{p} \cdot L_{m}(1-f(Q)) \cdot i_{q S}^{*}}{\pi\left(\frac{L_{r}}{R_{r}}-\frac{L_{m f}(Q)}{R r}\right) \lambda_{d r}}$

The decoupling control method uses a dual current controller, that utilized to provide the required regulatory voltages to the space vector pulse width modulation inverter is given as:

$V_{d s}^{*}=($ current controller $)\left(i_{d s}^{*}-i_{d s}\right)-\frac{\pi}{\tau_{p}} V_{e} L_{\sigma}(Q) i_{q s}^{*}$

$V_{q S}^{*}=($ current controller $)\left(i_{q s}^{*}-i_{q S}\right)+\frac{\pi}{t_{p}} V_{e} L_{\sigma}(Q) i_{d s}^{*}+\frac{P \cdot L_{m} \pi}{L_{r} \tau_{p}} V_{r} \lambda_{d r}$

Where $L_{\sigma}(Q)$ is the leakage inductance that represented by:

$L_{\sigma}(Q)=L_{S}-L_{m} f(Q)-\left(L_{m}(1-f(Q))\right)^{2} /\left(L_{r}-L_{m} f(Q)\right.$

\section{A 3-Phase Inverter Depend on Space Vector Pulse Width Modulation}

SVPWM (space vector pulse width modulation) is a popular way for controlling the threephase voltage source inverters (VSI)in applications such as control of induction motors and permanent magnet synchronous motors. The main purpose beyond SVPWM is to divide the 2dimensional plane into six similar areas, each area has named a sector as demonstrated in Fig 2. Each sector is determined by four vectors, two vectors from these four vectors $\left(v_{i}, v_{i+1}\right.$ where $i \epsilon\{1, \ldots 5\})$ are named active vectors because when supplied these vectors to the power circuit will produce an output voltage larger than zero, while the other two vectors $\left(V_{0}\right.$ and $\left.V_{7}\right)$ are named inactive vectors because the entire switches will be off or on [17], [18].

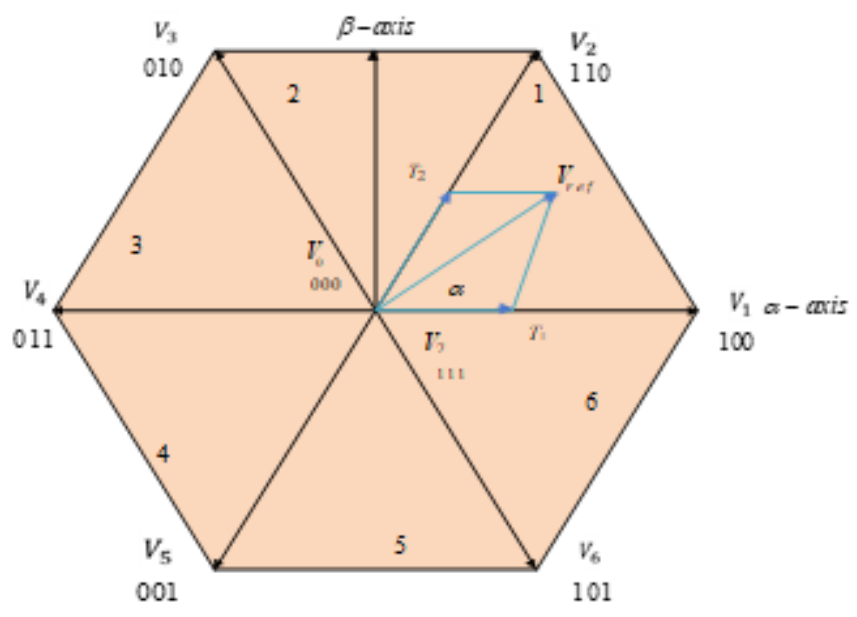

Fig 2. SVPWM 2-D plot. 


\section{Control Design}

\subsection{LIM Drive with PID as Velocity Controller}

The PID controller will be used to regulate the velocity of the LIM in the first method of IFOC of the LIM drive. Fig 3. depicts the PID controller's principle [19]. PID controllers have 3 main control modes: proportional, integral, and derivative. A PID controller has no idea what performance is required to get the system to the set point. It directs the output in the direction of the process's potential to access the setpoint, and it relies on feedback to do so [20].

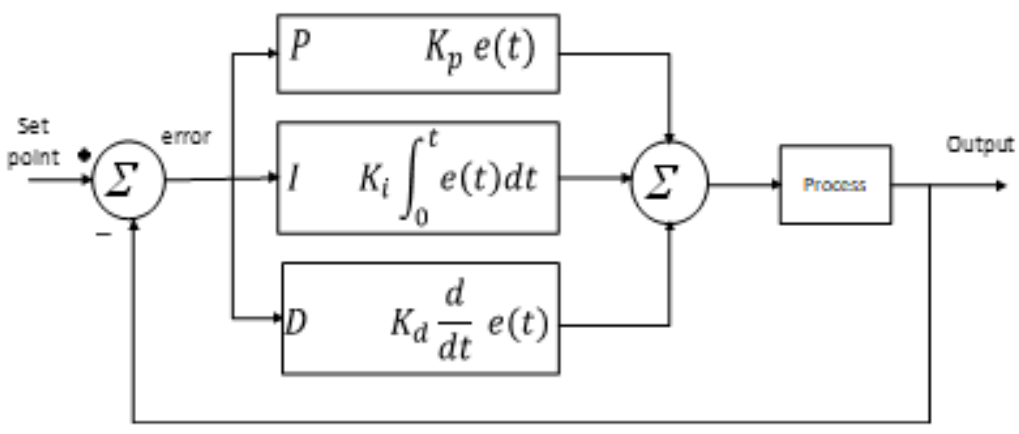

Fig 3. PID control circuit diagram.

\subsection{Model Predictive Control as Velocity Controller for LIM Drive}

MPC is a commonly used approach in the industry for dealing with control problems that are multivariable and constrained. The algorithm of the MPC is primarily based on [21]:

1. A dynamic internal model of the process,

2. The timeline of previous control actions, and

3. A cost function for optimizing over the prediction horizon.

Model predictive control's key theory is to select a control action by resolving an optimum control issue online repeatedly. This attempts to minimize a performance criterion over the future horizon, perhaps with restrictions on the manipulated inputs and outputs, where future behaviour is calculated using a plant model. There are problems engender with ensuring the stability of closed-loop, reducing online computations, and knob with the model uncertainty. The importance of this control technique becomes apparent when the system's path is determined in advance, as in the case of machine tools, chemical processes, or robots. An easy block diagram depicting the MPC controller's basic structure is demonstrated in Fig 4. In this diagram, a model is utilized to forecast future outputs of the plant using past and present values as well as suggested optimal future control behaviour. The optimizer calculates these actions considering the cost function (which considers future monitoring error) and restrictions. It's worth noting that the control signal is calculated using the system model's expected output and the actual error [21]. 


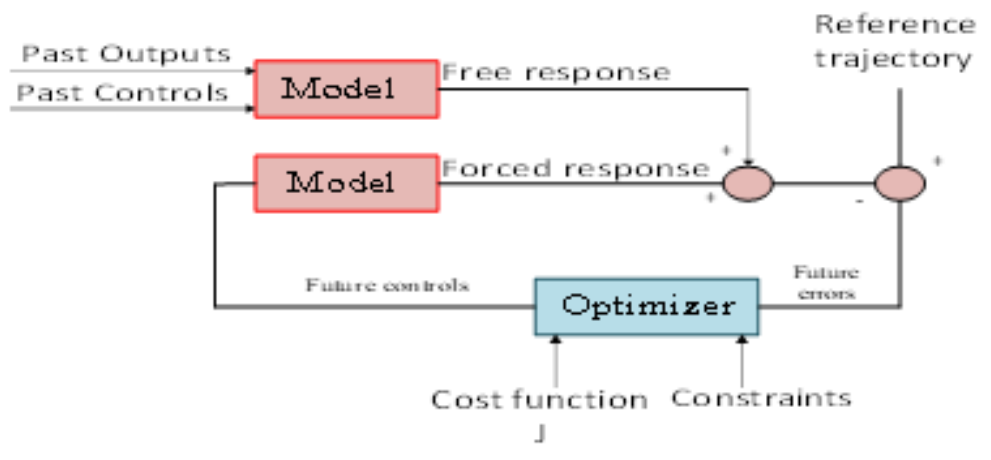

Fig 4. Shows the MPC controller's basic structure.

The overall goal is to reduce the output future error to zero with the least amount of input effort possible. In Generalized Predictive Control, for example, the cost function to be minimalized is a weighted sum of square expected errors and square future control values [21].

$J\left(N_{1}, N_{2}, N_{u}\right)=\sum_{j=N_{1}}^{N_{2}} \beta(j)\left[y^{\wedge}(k+j \mid k)-w(k+j)\right]^{2}+\sum_{j=1}^{N_{u}} \lambda(j)[u(k+j-1)]^{2}$

The $\mathrm{J}$ represents the cost function, which is concerned with the error signal minimization, the output's lower and upper prediction horizons denoted by $N_{1}$ and $N_{2}$ respectively, the control horizon is signified by $N_{u}, \beta(j)$ and $\lambda(j)$ denotes a weighting factor, $y^{\wedge}$ is the forecasting output, the reference trajectory over the future horizon is denoted by the $\omega$, the control signal is represented by a latter $u$, and the predictive horizons are denoted by $j$. The sampling instant is denoted by the letter $\mathrm{k}$ and $j \mid k$ denotes that at time $\mathrm{k}, i$ will perform iteration $j$.

The control horizon permits for a reduction in the number of calculated future controls based on the relationship.

$\Delta u(k+j)=0$ for $j \geq N_{u}$

The cost function can include constraints on the control signal, as well as changes in the control signal and output signal.

$u_{\min } \leq u(k) \leq u_{\max }$

$\Delta u_{\min } \leq \Delta u(k) \leq \Delta u_{\max }$

$y_{\min } \leq y(k) \leq y_{\max }$

While keeping the Constraints in mind, the solution of (20) offers the best control signal sequence over the horizon. The motor's transfer function can be calculated using the indirect field-oriented technique as follows:

Transfer Functiom $=\frac{V}{F_{e}-F_{L}}=\frac{1}{M S+B}$

For ease of execution, the simplistic LIM linearized model defined by (25) is used in the MPC controller's structure. 


\section{Linear Induction Motor with Suggested IFOC}

Fig 5. displays the block diagram of the LIM drive system, which contains the PID or MPC controllers. The measured velocity is utilized for closed-loop control that is being compared to the reference velocity to get the $i_{q s}^{*}$.

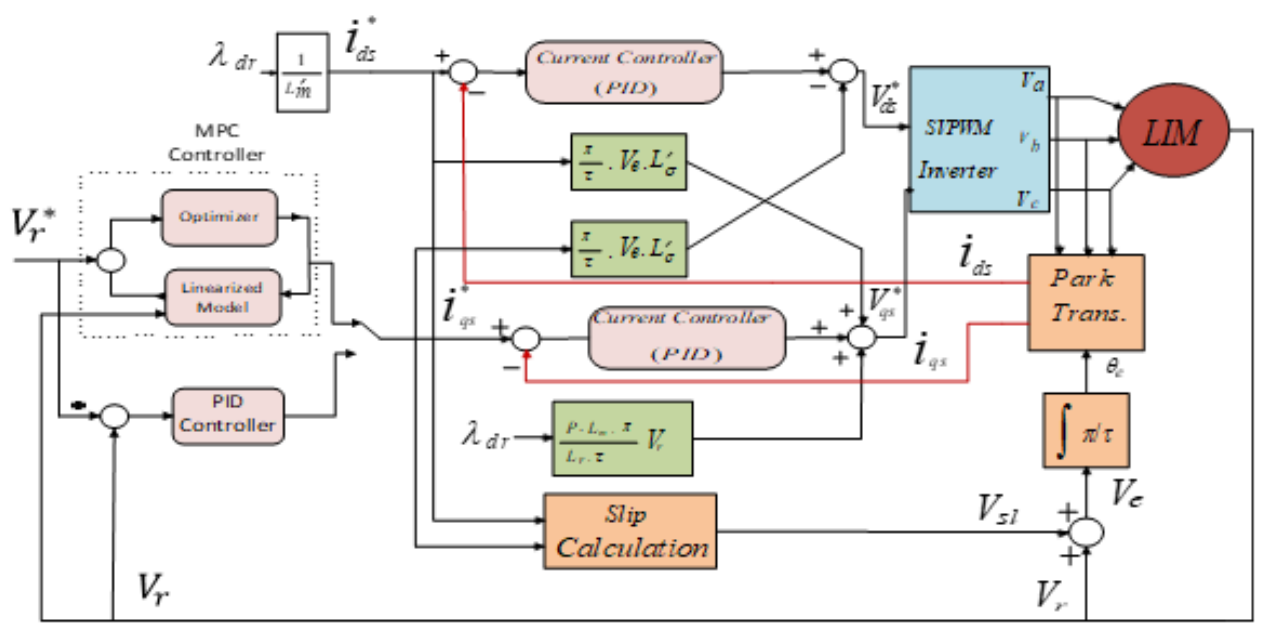

Fig 5. Linear induction motor drive with PID or MPC as a velocity controller.

\section{Results and Discussion}

To verify the feasibility of the suggested systems and to compare the two controllers' performances, computer simulations were used. This was done using the MATLAB / Simulink software kit. The LIM parameters utilize in this work are specified in Table 2.

Table 2. The parameters of LIM.

\begin{tabular}{lc}
\hline \multicolumn{1}{c}{ Parameters } & values \\
\hline $\mathrm{P}$ & 4 \\
$\tau_{p}(\mathrm{~m})$ & 0.0465 \\
$R_{S}(\Omega)$ & 13.2 \\
$R_{r}(\Omega)$ & 11.78 \\
$L_{S}(H)$ & 0.42 \\
$L_{r}(H)$ & 0.42 \\
$L_{m}(H)$ & 0.4 \\
$\mathrm{M}(\mathrm{kg})$ & 4.775 \\
$\mathrm{~B}(\mathrm{~kg} / \mathrm{sec})$ & 53 \\
\hline
\end{tabular}

The response of the PID controller versus the MPC controller for LIM drive velocity control is seen in Fig 6. During the start-up time, the PID controller has a poor transient response. In contrast to the MPC controller, it gets a long time to rise. When there is a load disruption (200 $\mathrm{N})$, the PID controller's response is greatly impacted, as seen in the figure. The suggested 
controller is also investigated under parameter uncertainty. In this scenario, the secondary resistance is increased by $25 \%$ in the LIM model, although it is held at its nominal value in the slip calculator. Also, the mover mass rose by $50 \%$ in the motor model only, this case is showed in Fig 7.

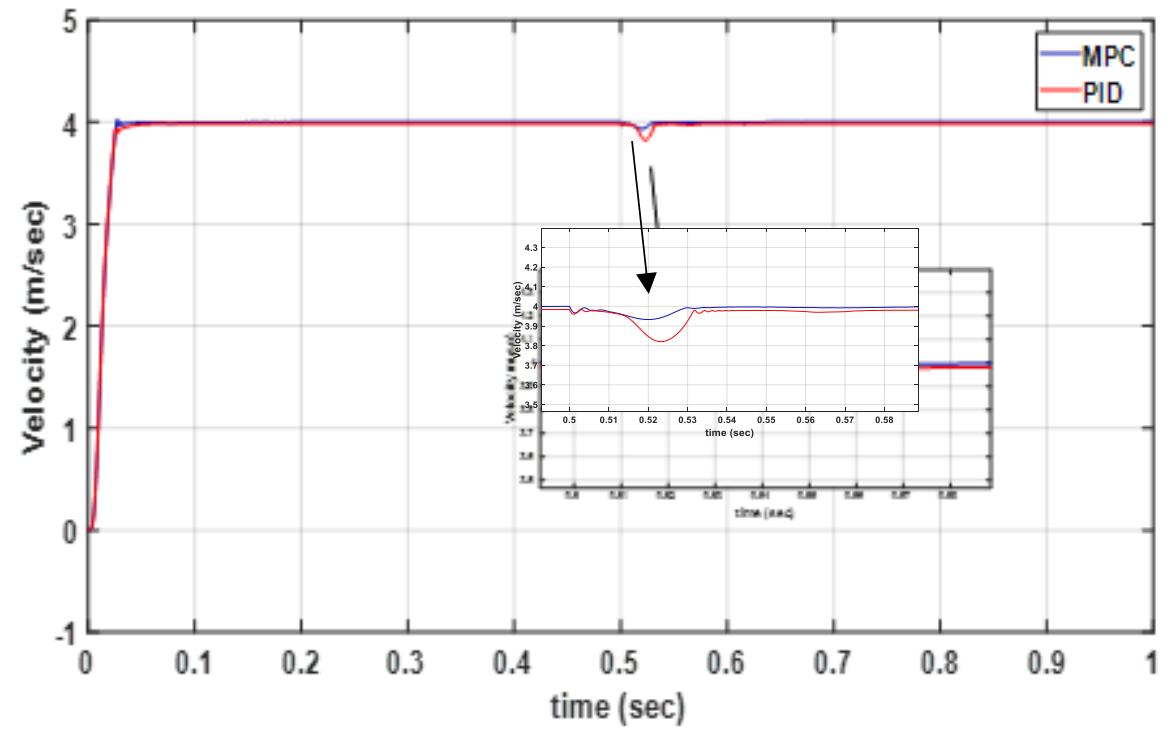

Fig 6. The MPC controller's response of velocity relative to the PID controllers at load disruption.

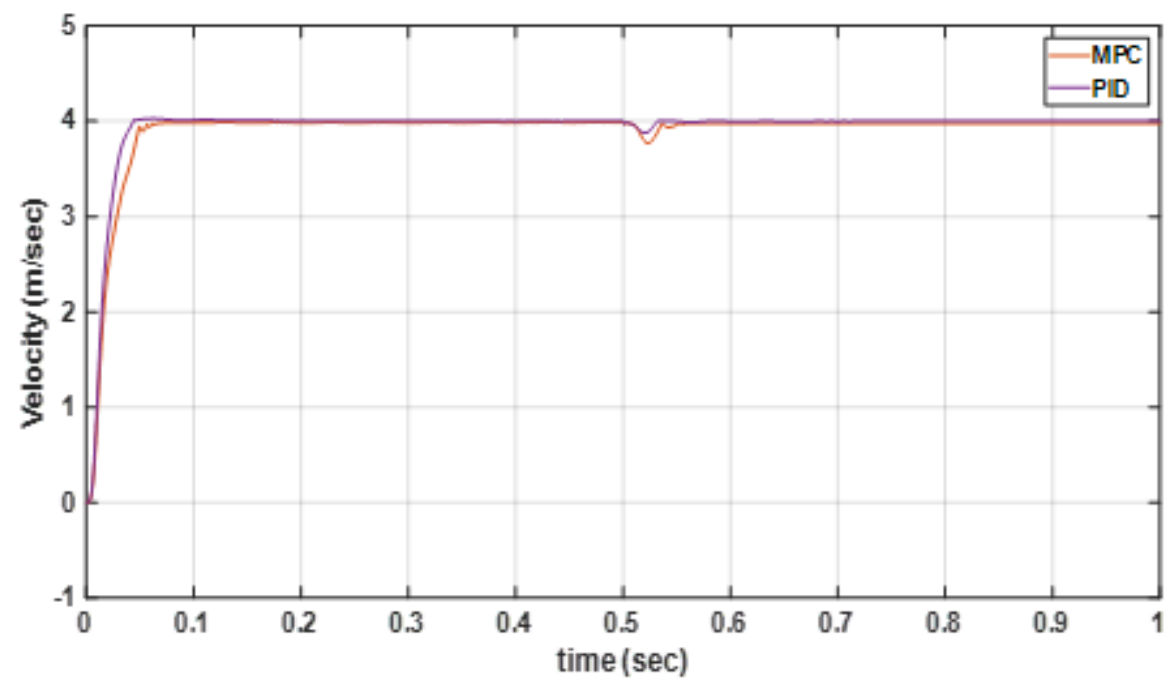

Fig 7. The MPC controller's response of velocity relative to the PID under change of load and parameters variation. 


\section{Conclusion}

Using of the MPC and PID controllers as velocity controllers of the LIM drive has been successfully demonstrated in this study. In addition, the MPC's response is compared to that of a standard PID controller. In the simulation, the LIM drive's output with the model predictive control controller and the PID controller was evaluated. The findings revealed that the model predictive control controller has a fast response time and is resilient in the face of parameter instability and load disturbances.

\section{References}

[1] Hamzehbahmani H. Modeling and simulating of single side short stator linear induction motor with the end effect. Journal of electrical engineering. 2011;62(5):302-8.

[2] Hassan A, Mohamed YS, Mohamed TH, editors. Robust control of a field oriented linear induction motor drive. 2006 Eleventh International Middle East Power Systems Conference; 2006: IEEE.

[3] Mannan MA, Murata T, Tamura J, Tsuchiya T, editors. Indirect field oriented control for high performance induction motor drives using space vector modulation with consideration of core loss. IEEE 34th Annual Conference on Power Electronics Specialist, 2003 PESC'03; 2003: IEEE.

[4] Bendjedia M, Tehrani K, Azzouz Y. Design of RST and fractional order PID controllers for an induction motor drive for electric vehicle application. 2014.

[5] Huang Y, Yasunobu S, editors. A general practical design method for fuzzy PID control from conventional PID control. Ninth IEEE International Conference on Fuzzy Systems FUZZ-IEEE 2000 (Cat No 00CH37063); 2000: IEEE.

[6] Diab AAZ, Kotin DA, Pankratov VV, editors. Speed control of sensorless induction motor drive based on model predictive control. 2013 14th International Conference of Young Specialists on Micro/Nanotechnologies and Electron Devices; 2013: IEEE.

[7] Salem FM, Mosaad MI, Awadallah MA. A comparative study of MPC and optimised PID control. International Journal of Industrial Electronics and Drives. 2015;2(4):242-50.

[8] Efheij H, Albagul A, Albraiki NA, editors. Comparison of model predictive control and PID controller in real time process control system. 2019 19th International Conference on Sciences and Techniques of Automatic Control and Computer Engineering (STA); 2019: IEEE.

[9] Kazraji SM, Feyzi M, Sharifian MB, Tohidi S. Fuzzy Predictive Force Control (FPFC) for Speed Sensorless Control of Single-side Linear Induction Motor. Engineering, Technology \& Applied Science Research. 2017;7(6):2132-8.

[10] Saleh AL, Obaid BA, Obed AA. Motion control of linear induction motor based on optimal recurrent wavelet neural network-PID controller. International Journal of Engineering \& Technology. 2018;7(4):2028-34.

[11] Xu W, Zhang Y, Zeng C, Xiao X, editors. Rotor field oriented control of linear induction machine based on fuzzy self-adapting PI controller. 2012 IEEE International Symposium on Industrial Electronics; 2012: IEEE.

[12] Saleh AL, Obed AA, Al-Yasir YI, Elfergani IT, Rodriguez J, Clarke RW, et al. Anti-windup scheme based on 2DOF-PI $\lambda \mathrm{D} \mu$ controller for velocity tracking of linear induction motor. International Transactions on Electrical Energy Systems. 2019;29(12):e12134.

[13] Shadabi H, Sadat AR, Pashaei A, Sharifian M. Speed Control of Linear Induction Motor Using DTFC Method Considering end-effect Phenomenon. International Journal on Technical and Physical Problems on Engineering. 2014;6(4):75-81.

[14] Da Silva E, Dos Santos E, Machado P, De Oliveria M, editors. Vector control for linear induction motor. IEEE International Conference on Industrial Technology, 2003; 2003: IEEE.

[15] Boucheta A, Bousserhane I, Hazzab A, Sicard P, Fellah M. Speed control of linear induction motor using sliding mode controller considering the end effects. Journal of Electrical Engineering and Technology. 2012;7(1):34-45. 
[16] Hamedani P, Shoulaie A, editors. Indirect field oriented control of linear induction motors considering the end effects supplied from a cascaded H-bridge inverter with multiband hystersis modulation. 4th Annual International Power Electronics, Drive Systems and Technologies Conference; 2013: IEEE.

[17] Hendawi E, Khater F, Shaltout A, Egypt G. Analysis, simulation and implementation of space vector pulse width modulation inverter. Power. 2006;4(T6):T2.

[18] Kubeitari M, Alhusayn A, Alnahar M. Space vector PWM simulation for three phase DC/AC inverter. World academy of science, engineering and technology. 2012;6(12):1402-7.

[19] Hartono H, Sudjoko R, Iswahyudi P, editors. Speed Control of Three Phase Induction Motor Using Universal Bridge and PID Controller. Journal of Physics: Conference Series; 2019: IOP Publishing.

[20] Devi K, Gautam S, Nagaria D. Speed control of 3-phase induction motor using self-tuning fuzzy PID controller and conventional PID controller. International Journal of Information \& Computation Technology. 2014;4(12):1185-93.

[21] Diab AZ, Kotin D, Anosov V, Pankratov V, editors. A comparative study of speed control based on MPC and PI-controller for Indirect Field oriented control of induction motor drive. 2014 12th International Conference on Actual Problems of Electronics Instrument Engineering (APEIE); 2014: IEEE. 